\title{
Intraoperative mild hypothermia does not increase the plasma concentration of stress hormones dur- ing neurosurgery
}

\section{[L'hypothermie peropératoire bénigne n'entraîne pas d'augmentation de la con-} centration plasmatique des hormones $d u$ stress pendant la neurochirurgie]

Oak Za Chi MD, * Young Kyoo Choi MD,† Doo Ik Lee MD,† Young Sul Kim MD,‡ Isidore Lee MD*

Purpose: To determine how mild hypothermia $\left(34^{\circ} \mathrm{C}\right)$ affects the hemodynamic and the stress hormonal responses intraoperatively and during extubation in patients undergoing cerebral aneurysm surgery.

Methods: After induction, anesthesia was maintained with 1.2\% isoflurane and $50 \%$ nitrous oxide. For the normothermia and the hypothermia groups, the body temperature was maintained at 36.9 $\pm 0.3^{\circ} \mathrm{C}$ and $34.2 \pm 0.2^{\circ} \mathrm{C}$ respectively up to the recovery room. Hemodynamic changes were recorded continuously. Stress hormones comprising epinephrine, norepinephrine, ADH, ACTH, and cortisol were measured at the awake control, intraoperative, and extubation periods.

Results: Vital signs of the intraoperative and postextubation time periods were not significantly different between the normothermia and hypothermia groups except for a statistically lower pulse rate intraoperatively in the hypothermia group $(P<0.05)$. In the control awake state, all five hormonal concentrations were similar between the two groups. Intraoperatively, all of the hormonal levels tended to be lower in the hypothermia group compared to the normothermia group, but only the epinephrine level decreased sufficiently to reach statistical significance $(P<0.05)$. During extubation, all stress hormone concentrations, except norepinephrine, were lower in the hypothermia group (epinephrine: $P<0.05$; $A D H: P$ $<0.05$; ACTH: $P<0.05$; cortisol: $P<0.05$ )

Conclusions: Our data suggest that intraoperative mild hypothermia neither significantly affects the blood pressure response nor increases the concentrations of stress hormones intraoperatively. Furthermore, mild hypothermia significantly decreased the plasma concentrations of stress hormones during the extubation period.
Objectif : Déterminer comment l'hypothermie bénigne $\left(34^{\circ} \mathrm{C}\right)$ modifie les réponses hémodynamiques et celles des hormones du stress pendant l'opération et l'extubation chez des patients qui subissent une intervention pour anévrisme cérébral.

Méthode : L'anesthésie a été maintenue avec l'isoflurane à 1.2\% et du protoxyde d'azote à $50 \%$. Sous normothermie et hypothermie, la température du corps a été de $36,9 \pm 0,3^{\circ} \mathrm{C}$ et $34,2 \pm$ $0,2{ }^{\circ} \mathrm{C}$ respectivement jusqu'au transfert en salle de réveil. L'enregistrement des données hémodynamiques a été continu. Les hormones du stress (épinéphrine, norépinéphrine, ADH, ACTH et cortisol) ont été mesurées à l'état d'éveil, pendant l'opération et à l'extubation.

Résultats : Les signes vitaux peropératoires et post-extubation n'ont pas été significativement différents sous normothermie ou hypothermie sauf pour une fréquence cardiaque peropératoire statistiquement plus faible sous hypothermie $(P<0,05)$. À la mesure vigile témoin, les cinq concentrations hormonales ont été semblables dans les deux groupes. Les niveaux hormonaux peropératoires tendaient à rester plus bas sous hypothermie, comparée à la normothermie, mais seule la baisse d'épinéphrine a été statistiquement significative $(P<0,05)$. À l'extubation, les concentrations hormonales, sauf celle de la norépinéphrine, étaient plus faibles sous hypothermie (épinéphrine : $P<0,05 ; \mathrm{ADH}: P<0,05 ; \mathrm{ACTH}: P$ $<0,05$; cortisol : $P<0,05$ )

Conclusion : Nos données permettent de dire que l'hypothermie peropératoire bénigne ne modifie pas la tension artérielle et n'augmente pas les concentrations d'hormones du stress de façon significative pendant l'opération. En outre, l'hypothermie bénigne fait baisser sensiblement les concentrations d'hormones du stress après l'extubation.

From the Department of Anesthesia, ${ }^{*}$ University of Medicine and Dentistry of New Jersey - Robert Wood Johnson Medical School, New From the Department of Anesthesia, ${ }^{*}$ University of Medicine and Dentistry of New Jersey - Robert Wood Johnson Medical School, New
Brunswick, New Jersey, USA; the Departments of Anesthesiology, $†$ and Internal Medicine, Kyung Hee University Medical School, Seoul, Brunswick, New Jersey, USA; the Departments of Anesthesiology, $\uparrow$ and Internal Medicine, $f$ Kyung Hee University Medical School, Seoul,
Korea.

Address correspondence to: Dr. Oak Za Chi, Department of Anesthesia, University of Medicine and Dentistry of New Jersey - Robert Wood Johnson Medical School, 125 Paterson Street, Suite 3100, New Brunswick, New Jersey 08901-1977, USA. Phone: 732-235-7827; Fax: 732-235-6131; E-mail: chi@umdnj.edu

Accepted for publication March 9, 2001.

Revision accepted May 2, 2001. 
$\mathrm{E}$ VEN in patients who suffer from very mild intraoperative hypothermia $\left(35.3 \pm 0.1^{\circ} \mathrm{C}\right)$, postoperative norepinephrine concentrations and blood pressure are elevated compared to normothermic patients. ${ }^{1}$ However, it is not clear whether mild intraoperative hypothermia enhances stress responses during surgery since, on the other hand, it has been reported that hypothermia reduces the minimum alveolar concentration (MAC) of anesthetics by about $5 \%$ per $1^{\circ} \mathrm{C} .{ }^{2,3}$

We hypothesized that, under a constant anesthetic concentration or dose, under hypothermic conditions, the stress hormonal and hemodynamic responses to the same stimuli could be decreased in hypothermic patients. In this study, during cerebral aneurysm surgery under anesthesia with 1.2\% isoflurane and 50\% nitrous oxide, the body temperature was decreased to $34^{\circ} \mathrm{C}$. The plasma concentrations of epinephrine, norepinephrine, $\mathrm{ADH}, \mathrm{ACTH}$, and cortisol were determined and hemodynamic changes were recorded during the preanesthesia, intraoperative, and extubation periods.

\section{Methods}

This study was approved by the Kyung Hee University Human Studies Committee. Forty-one adult men and women scheduled for elective intracranial aneurysm surgery, ASA physical status I-III and modified HuntHess' Grade 0-2, were selected for this study and a written informed consent was obtained.

The patients were premedicated with glycopyrrolate $0.005 \mathrm{mg} \cdot \mathrm{kg}^{-1}$ and midazolam $0.05 \mathrm{mg} \cdot \mathrm{kg}^{-1} \mathrm{im}$ $60 \mathrm{~min}$ preoperatively. Anesthesia was induced with thiopentone $4-6 \mathrm{mg} \cdot \mathrm{kg}^{-1}$ and vecuronium 0.15 $\mathrm{mg} \cdot \mathrm{kg}^{-1}$, and maintained with $50 \%$ nitrous oxide in oxygen and $1.2 \%$ isoflurane until the end of surgery, except for a few minutes at a time to accommodate surgical stimuli.

Before induction, the tympanic temperature was measured with an infrared sensor (Thermoscan, San Diego, CA, USA). After induction, an esophageal temperature probe (Mon-a-therm, Mallincroft Medical, St. Louis, MO, USA) was placed at the distal end of the range of the maximal heart sound, where the esophageal temperature correlates well with the tympanic membrane temperature. ${ }^{4}$ Tympanic membrane temperature was recorded again after extubation and in the recovery room.

For the normothermia group $(n=21)$, a forced air blanket and a fluid warmer were used to keep the esophageal and tympanic temperature at $36.9 \pm$ $0.3^{\circ} \mathrm{C}$. For the hypothermia group $(n=20)$, after induction, active cooling was started with a water blanket and by maintaining low ambient temperatures in order to maintain a body temperature of $34.2 \pm$ $0.2^{\circ} \mathrm{C}$ up to the recovery room.

Blood samples for the analysis of plasma concentrations of stress hormones were obtained from the radial arterial cannula at the following time points:

\section{Awake control}

Ten minutes after insertion of the radial artery when the patient was calm and before induction of anesthesia.

\section{Intraoperative}

After the dura was opened and a constant esophageal temperature was observed for one hour, a constant anesthetic concentration of $1.2 \%$ isoflurane and $50 \%$ $\mathrm{N}_{2} \mathrm{O}$ was maintained for $20 \mathrm{~min}$ and during relatively quiet periods without strong surgical stimuli or significant blood losses.

\section{Extubation}

One minute before extubation, $1.5 \mathrm{mg} \cdot \mathrm{kg}^{-1}$ lidocaine was administered $i v$. Patients responded to verbal commands. Sampling of blood was performed one minute after extubation. Body temperature was the same as that of the intraoperative period.

Epinephrine and norepinephrine concentrations were determined using high performance liquid chromatography. ADH, ACTH and cortisol concentrations were determined using radioimmunoassay kits.

All data were analyzed using an analysis of variance. Change over time was evaluated using repeated measures of analysis of variance and the paired Student's t test with a Bonferroni correction for multiple compar-

TABLE Demographic and intraoperative variables

\begin{tabular}{|c|c|c|}
\hline & Normothermia & Hypothermia \\
\hline Number of patients & 21 & 20 \\
\hline Age & $49.7 \pm 12.9$ & $52.9 \pm 8.0$ \\
\hline Gender $(\mathrm{F} / \mathrm{M})$ & $11 / 10$ & $10 / 10$ \\
\hline Weight $(\mathrm{kg})$ & $63.1 \pm 10.9$ & $64.0 \pm 8.6$ \\
\hline Height $(\mathrm{cm})$ & $164.8 \pm 8.2$ & $164.5 \pm 6.2$ \\
\hline Duration of surgery $(\mathrm{min})$ & $321 \pm 138$ & $319 \pm 58$ \\
\hline $\begin{array}{l}\text { Incision to clipping of } \\
\text { aneurysm (min) }\end{array}$ & $186.0 \pm 85.4$ & $195.8 \pm 38.3$ \\
\hline Time to cool to $35^{\circ} \mathrm{C}(\mathrm{min})$ & & $100 \pm 34$ \\
\hline Time to cool to $34^{\circ} \mathrm{C}(\mathrm{min})$ & & $158 \pm 44$ \\
\hline $\begin{array}{l}\text { Time from discontinuation } \\
\text { of anesthesia to extubation }(\mathrm{min})\end{array}$ & $20.0 \pm 9.1$ & $22.3 \pm 7.3$ \\
\hline Shivering at the time of extubation & & \\
\hline $\begin{array}{l}\text { Number of patients } \\
\text { Maintenance temperature }\left({ }^{\circ} \mathrm{C}\right)\end{array}$ & 0 & 2 \\
\hline $\begin{array}{l}\text { Intraoperative and extubation } \\
\text { periods }\end{array}$ & $36.9 \pm 0.3$ & $34.2 \pm 0.2$ \\
\hline
\end{tabular}

Data are mean $\pm S D$ 


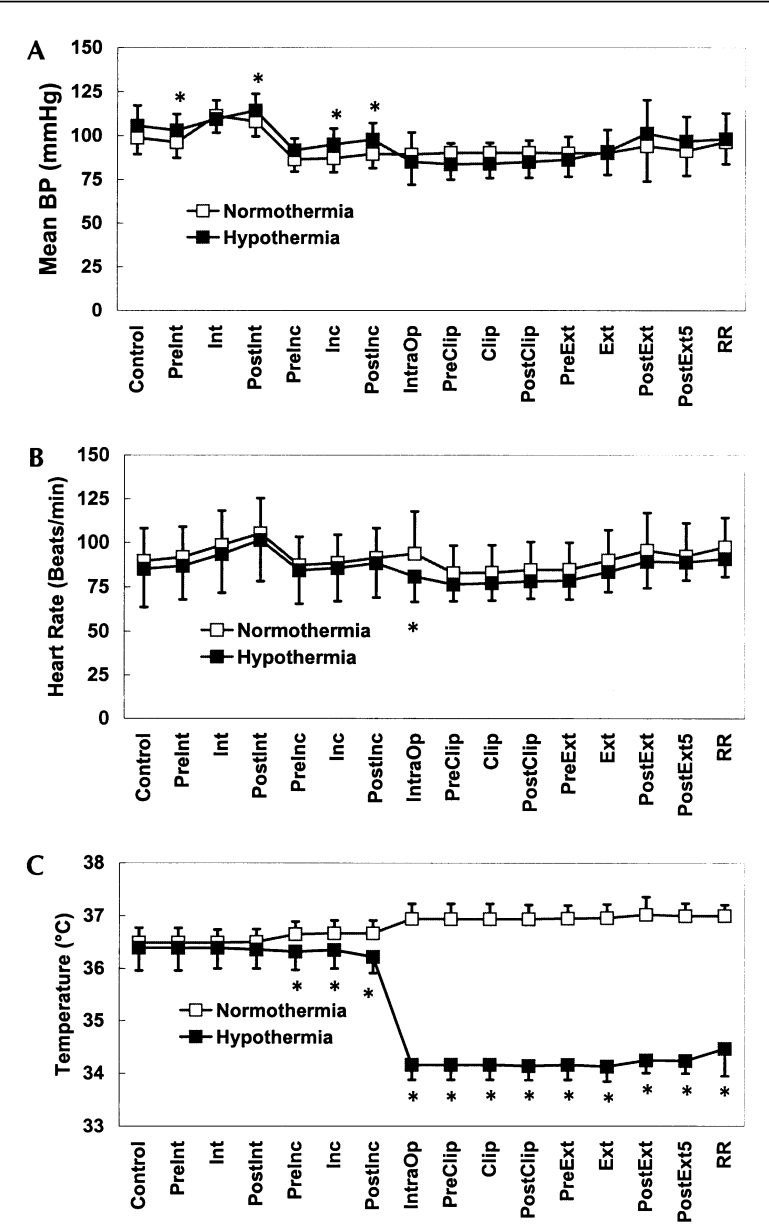

FIGURE 1 Mean blood pressure (A), heart rate (B), and body temperature $(\mathrm{C})$ during experimental periods. Data are expressed as mean $\pm \mathrm{SD}$. * Significantly different from the normothermia group. Control=awake control state; PreInt=right before intubation; Int=at the time of intubation; PostInt=l min after intubation; PreInc=right before skin incision; Inc=at the time of skin incision; PostInc $=1$ min after skin incision; IntraOp=during surgery when a constant tem seras ince surgery when a constat tenperate was min PreClip=right before clipping of aneurysm; Clip=at the time of clipping of aneurysm; PostClip=1 min after clipping of aneurysm PreExt=right before extubation; Ext=at the time of extubation; PostExt=1 min after extubation; PostExt5 $=5$ min after extubation; $\mathrm{RR}=15 \mathrm{~min}$ after arriving in the recovery room.

isons. The difference between the two groups was evaluated using the Student's t test. Significance was taken as $P<0.05$.

\section{Results}

There were no differences in demographic data (Table), blood gases, hemoglobin, and glucose between the
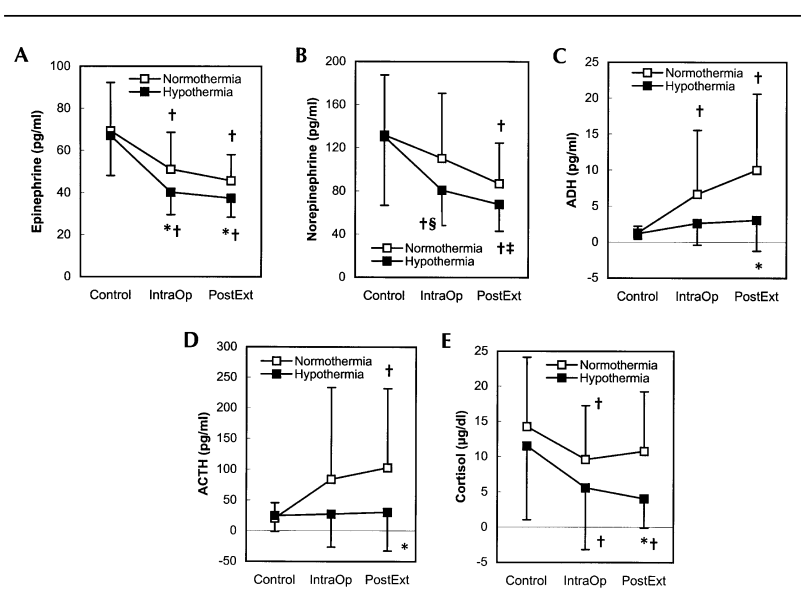

FIGURE 2 Plasma concentrations of the stress hormones. (A) epinephrine; (B) norepinephrine; (C) ADH; (D) ACTH; (E) cortisol. Data are expressed as mean $\pm \mathrm{SD}$. * Significantly different from the normothermia group; $\uparrow$ significantly different from the control state in the same group; $\ddagger$ significantly different from the intraoperative period in the same group; $\$$ significantly different from the postextubation period in the same group. Control=awake control state; IntraOp=during surgery; PostExt=1 min after extubation.

normothermia and hypothermia groups. The vital signs and temperature changes during the study periods are shown in Figure 1. After hypothermia was induced, the vital signs were similar between the two groups except that the intraoperative heart rate was lower in the hypothermia group $(P<0.05)$.

In both the normothermia and the hypothermia groups, intraoperative and postextubation concentrations of epinephrine, norepinephrine, and cortisol were lower than prior to anesthesia (control; Figure 2). However, the levels of ADH and ACTH were higher or unchanged from the control level in both groups. Intraoperatively, all concentrations of stress hormones tended to be lower in the hypothermia group compared to the normothermia group, but only the epinephrine concentration decreased sufficiently to reach statistical significance $(P<0.05)$. At the postextubation time point, all stress hormones $(P<0.05)$, except norepinephrine, were lower in the hypothermia compared to the normothermia group (Figure 2).

\section{Discussion}

Our data suggest that mild intraoperative hypothermia does not significantly affect the blood pressure response and does not increase the plasma concentrations of stress hormones at the intraoperatively. Furthermore, 
mild hypothermia significantly decreased the concentrations of stress hormones during extubation.

Our hemodynamic data suggest that the level of anesthesia was adequate to effectively suppress most of the stimulation in both groups of patients. Decreased sympathetic activity by isoflurane, ${ }^{5,6}$ lidocaine prior to extubation, residual anesthetics, or the time lag between the stressful stimulus and the release of hormones in the plasma could explain the lower catecholamine concentrations during the intraoperative and the extubation periods compared to the awake state. The higher pituitary hormone concentrations reported in this study are similar to those of other studies where $\mathrm{ADH}$ was increased during and after surgery with various anesthetic agents. ${ }^{7,8}$

While mild hypothermia may decrease the adrenopituitary hormonal response to stress, there were no clinically significant differences in hemodynamic variables between groups, suggesting that factors other than the hormonal response to stress were responsible for the observed hemodynamic stability.

Intraoperative hypothermia has been associated with prolonged postanesthetic recovery, ${ }^{9}$ higher drug plasma concentrations, ${ }^{10}$ and a lower MAC of volatile anesthetic agents. ${ }^{2,3}$ Our intraoperative and extubation hormonal data suggest that mild hypothermia may further lower the stress hormonal response at the constant dose of isoflurane or $i v$ lidocaine.

In conclusion, our data suggest that, for a given dose of anesthetic, mild hypothermia may contribute to decrease stress hormonal responses intraoperatively and after extubation.

\section{Acknowledgement}

The authors wish to thank Patricia A. Sheffield, M.A. for her expert editorial assistance.

\section{References}

1 Frank SM, Higgins MS, Breslow MJ, et al. The catecholamine, cortisol, and hemodynamic responses to mild perioperative hypothermia. Anesthesiology 1995; 82: 83-93.

2 Eger II EI, Johnson BH. MAC of I-653 in rats, including a test of the effect of body temperature and anesthetic duration. Anesth Analg 1987; 66: 974-6.

3 Vitez TS, White PF, Eger II. Effects of hypothermia on halothane MAC and isoflurane MAC in the rat. Anesthesiology 1974; 41: 80-1.

4 Stoen $R$, Sessler $D l$. The thermoregulatory threshold is inversely proportional to isoflurane concentration. Anesthesiology 1990; 72: 822-7.

5 Deegan R, He HB, Wood AJJ, Wood M. Effect of enflurane and isoflurane on norepinephrine kinetics: a new approach to assessment of sympathetic function during anesthesia. Anesth Analg 1993; 77: 49-54.

6 Seagard JL, Elegbe EO, Hopp FA, et al. Effects of isoflurane on the baroreceptor reflex. Anesthesiology 1983; 59: 511-20.

7 Monk TG, Mueller M, White PF. Treatment of stress response during balanced anesthesia. Anesthesiology 1992; 76: 39-45.

8 Bormann BV, Weidler B, Dennhardt R, Sturm G, Scheld $H H$, Hempelman $G$. Influence of epidural fentanyl on stress-induced elevation of plasma vasopressin $(\mathrm{ADH})$ after surgery. Anesth Analg 1983; 62: 727-32.

9 Lenbardt R, Marker E, Goll V, et al. Mild intraoperative hypothermia prolongs postanesthetic recovery. Anesthesiology 1997; 87: 1318-23.

10 Leslie K, Sessler DI, Bjorksten AR, Moayeri A. Mild hypothermia alters propofol, pharmacokinetics and increases the duration of action of atracurium. Anesth Analg 1995; 80: 1007-14 